\title{
CHILD MORBIDITY DEMONSTRATED IN A GENERAL HOSPITAL
}

\author{
BY \\ E. M. POULTON \\ From Hackney Hospital, London
}

(Received for Publication January 30, 1950)

A fair picture of adult morbidity can be obtained from sickness-absenteeism rates in various industries, but no such information is available for children.

Several analyses have been made of the admissions to children's hospitals (Baber, 1939; Smellie, 1949), and Tisdall, Brown, and Kelly (1930) studied the age of onset, sex distribution, and seasonal incidence of 25 diseases from admissions to the Hospital for Sick Children, Toronto, and from the records of the Toronto Department of Public Health. In America, Collins (1948) studied the extent of illness in the first year of life by canvassing.

Children admitted to a general hospital form a better sample of sick children in the general population than those admitted to children's hospitals. Hackney Hospital is a general hospital of 700 beds, containing acute medical, surgical, obstetric, gynaecological, and chronic wards. There is in addition an infants' ward of 30 cots. During the period under review, August 1, 1947, to July 31, 1949 , there were 3,159 admissions of children of 15 years and under, amounting to one-sixth of the total admissions. Infants born in the hospital are not included in this series unless they were subsequently readmitted.

\section{Age and Sex Distribution}

The 3,159 admissions were classified into four age groups, and each group divided by sex (Table 1). It can be seen that child morbidity is greatest in the first year of life and steadily decreases. At all ages

TABLE 1

Age and Sex Distribution of 3,159 Admissions

\begin{tabular}{|c|c|c|c|c|c|c|}
\hline Age & Group & (Years) & & Male & Female & Total \\
\hline $\begin{array}{r}\text { First year } \\
1-5 \\
6-10 \\
11-15\end{array}$ & $\begin{array}{l}\text { of life } \\
\ldots \\
\ldots \\
\ldots\end{array}$ & $\begin{array}{l}\cdots \\
\ldots \\
\ldots\end{array}$ & . & $\begin{array}{l}239 \\
740 \\
559 \\
352\end{array}$ & $\begin{array}{l}132 \\
463 \\
433 \\
241\end{array}$ & $\begin{array}{r}371 \\
1,203 \\
992 \\
593\end{array}$ \\
\hline
\end{tabular}

there is a general predominance of males over females.

\section{Chief Causes of Admission}

The causes of admission are classified as 'inflammatory' and 'non-inflammatory.' This is similar to Smellie's classification of 'infectious" and 'non-infectious.'

Inflammatory Group (1,436 Cases). The 11 commonest diseases in this group in order of frequency are: otitis media and mastoiditis, pneumonia, acute appendicitis, upper respiratory infections, asthma and bronchitis, suppurative tonsillitis, abscesses, rheumatism (all forms), lymphadenitis (all forms), acute laryngo-tracheitis and urinary infections. The frequency of these diseases classified by age groups is given in Table 2.

TABLE 2

INCIDENCE BY AGE OF COMMONEST INFLAMMATORY Diseases

\begin{tabular}{|c|c|c|c|c|c|}
\hline Disease & $\begin{array}{l}\text { Under } \\
1 \text { year }\end{array}$ & $\begin{array}{c}1-5 \\
\text { (years) }\end{array}$ & $\begin{array}{c}6-10 \\
\text { (years) }\end{array}$ & $\begin{array}{c}11-15 \\
\text { (years) }\end{array}$ & Total \\
\hline \multicolumn{6}{|l|}{ Otitis media and } \\
\hline $\begin{array}{l}\text { Pneumonia -. } \\
\text { Acute appen- }\end{array}$ & 73 & 97 & 25 & 11 & 206 \\
\hline dicitis & 0 & 23 & 52 & 79 & 154 \\
\hline $\begin{array}{l}\text { Disease of upper } \\
\text { respiratory } \\
\text { tract } \\
\text { Asthma and }\end{array}$ & 24 & 94 & 24 & 10 & 152 \\
\hline $\begin{array}{c}\text { bronchitis } \\
\text { Suppurative }\end{array}$ & 31 & 76 & 13 & 7 & 127 \\
\hline $\begin{array}{l}\text { tonsillitis } \\
\text { Abscesses } \\
\text { Rheumatism . } \\
\text { Lymphadenitis } \\
\text { Acute laryngo- }\end{array}$ & $\begin{array}{l}3 \\
4 \\
0 \\
3\end{array}$ & $\begin{array}{r}54 \\
29 \\
9 \\
30\end{array}$ & $\begin{array}{l}28 \\
17 \\
17 \\
11\end{array}$ & $\begin{array}{r}13 \\
21 \\
29 \\
6\end{array}$ & $\begin{array}{l}98 \\
71 \\
55 \\
50\end{array}$ \\
\hline $\begin{array}{l}\text { tracheitis } \\
\text { Urinary infec- }\end{array}$ & 10 & 13 & 3 & $\mathbf{0}$ & 26 \\
\hline tions $\quad \ldots$ & 4 & 4 & 11 & 6 & 25 \\
\hline Other diseases & 36 & 111 & 59 & 317 & 523 \\
\hline
\end{tabular}


Non-inflammatory Group (1,678 Cases). This group consists largely of cases admitted for the removal of tonsils or adenoids and for injuries. It also includes healthy children, mostly babies, admitted for the continuance of breast feeding.

TABLE 3

Commonest Non-Inflammatory Causes of admission

\begin{tabular}{|c|c|c|c|c|c|}
\hline Disease & 旁 & ? & 으월 & 吾兽 & Еँّ \\
\hline $\begin{array}{l}\text { Removal of tonsils } \\
\text { or adenoids } \\
\text { Injuries }\end{array}$ & $\begin{array}{l}1 \\
5\end{array}$ & $\begin{array}{l}218 \\
157\end{array}$ & $\begin{array}{l}398 \\
134\end{array}$ & $\begin{array}{r}125 \\
85\end{array}$ & $\begin{array}{l}742 \\
381\end{array}$ \\
\hline $\begin{array}{ll}\text { observation) } & \text {. } \\
\text { Healthy } & \text {.. } \\
\text { Circumcisions } & \text {. }\end{array}$ & $\begin{array}{l}1 \\
54 \\
42\end{array}$ & $\begin{array}{r}18 \\
4 \\
11\end{array}$ & $\begin{array}{r}35 \\
1 \\
2\end{array}$ & $\begin{array}{r}32 \\
2 \\
5\end{array}$ & $\begin{array}{l}86 \\
61 \\
60\end{array}$ \\
\hline $\begin{array}{l}\text { Removal of normal } \\
\text { appendix } \\
\text { Dyspepsia and acute }\end{array}$ & O & 4 & 13 & 14 & 31 \\
\hline gastritis 0 & 2 & 15 & 6 & 6 & 29 \\
\hline $\begin{array}{cc}c e l e s & \ldots\end{array}$ & $\begin{array}{r}4 \\
52\end{array}$ & $\begin{array}{l}19 \\
91\end{array}$ & $\begin{array}{r}2 \\
60\end{array}$ & $\begin{array}{r}3 \\
57\end{array}$ & $\begin{array}{r}28 \\
260\end{array}$ \\
\hline
\end{tabular}

The eight most common causes of admission are given in Table 3.

\section{Age Incidence of Causes of Admission}

The inflammatory diseases clearly fall into three groups with different age distributions. First there is a group, most frequent in the first year of life and diminishing in frequency as age advances, which consists of the respiratory infections (pneumonia, bronchitis, laryngo-tracheitis), and to a less marked extent the upper respiratory infections.

Secondly there is a group, uncommon in the first year of life, which is commonest in the age group 1-5 years, with the frequency falling in the higher age groups. This group consists of the pyogenic diseases: otitis media, suppurative tonsillitis, abscesses, and lymphadenitis.

The third group, in which the frequency rises throughout childhood, consists, most commonly, of acute appendicitis and rheumatism. Urinary infections, from the few cases present in the series, do not appear to follow either of these patterns.

The variation of frequency with age is shown for these three groups of diseases in Fig. 1. It will be

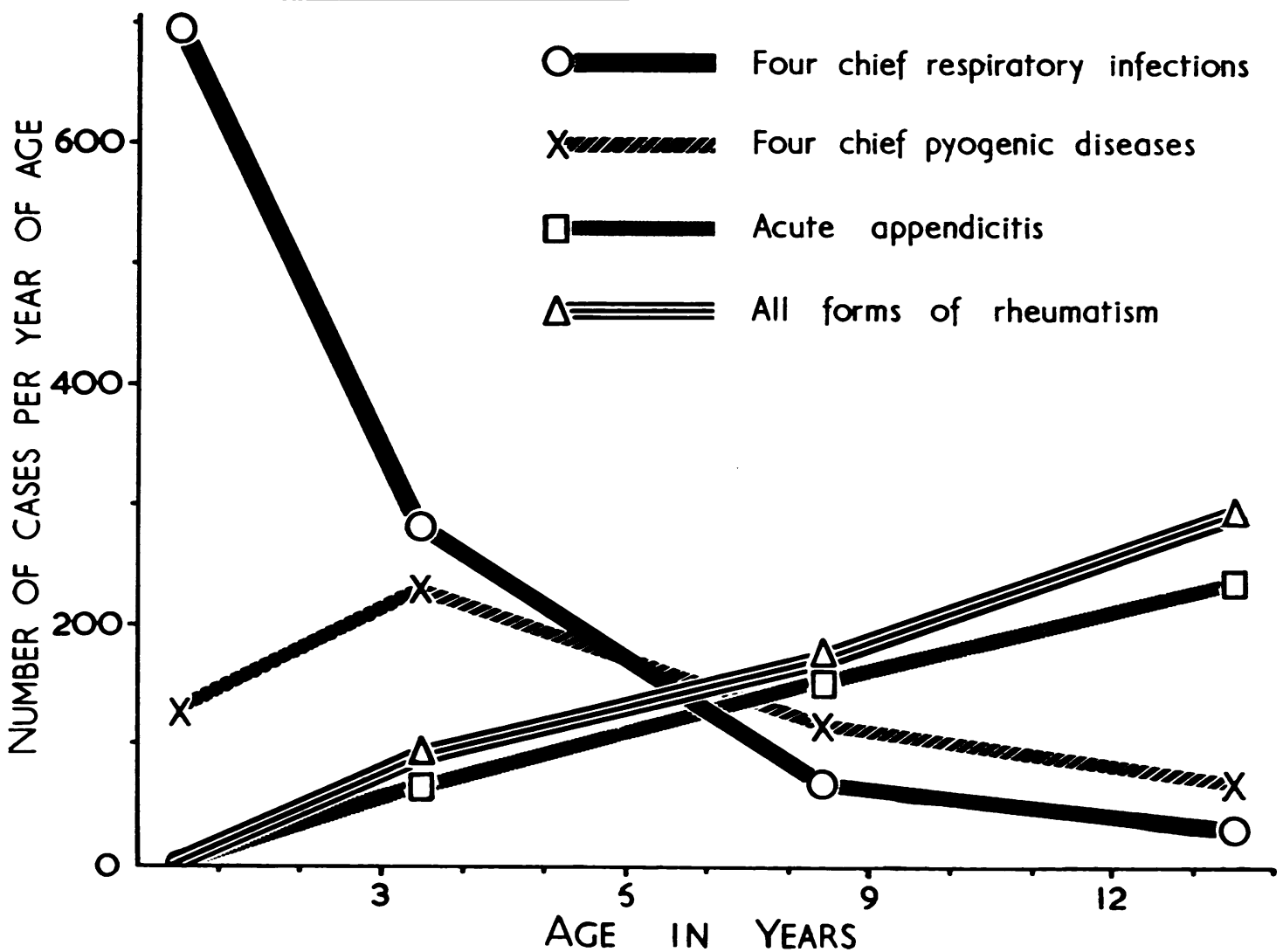

Fig. 1. 
seen that acute appendicitis and the rheumatic diseases increase in frequency in proportion to age, in direct contrast to the other two groups.

The non-inflammatory diseases are rare in the first year of life. Apart from the admissions of healthy babies and for circumcision, the commonest causes of admission in this group were feeding difficulties (17 cases), skin conditions (seven cases), and intussusception (five cases). This is in striking contrast to the findings of Smellie (1949) who gives pyloric stenosis, miscellaneous congenital abnormalities, feeding problems, harelip and cleft palate, erythroblastosis, and prematurity as the chief causes of admission in his ' non-infectious' group. Baber (1939) gives surgical conditions, congenital abnormalities, prematurity, and pyloric stenosis in that order.

Cases admitted with injuries can be classified into fractures and dislocations, concussion, lacerations, burns and scalds, and minor injuries. The age distribution of these various types of injury is given in Table 4.

TABLE 4

Cases Admitted OWing to InJury

\begin{tabular}{|c|c|c|c|c|c|}
\hline Type of Injury & 流㐫 & 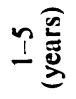 & 으 & 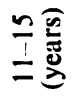 & E \\
\hline $\begin{array}{l}\text { Fractures and dis- } \\
\text { locations } \\
\text { Concussion and }\end{array}$ & 1 & 27 & 60 & 30 & 118 \\
\hline $\begin{array}{l}\text { fractured skull } \\
\text { Lacerations } \\
\text { Burns and scalds } \\
\text { Other minor injuries }\end{array}$ & $\begin{array}{l}0 \\
0 \\
2 \\
2\end{array}$ & $\begin{array}{l}33 \\
18 \\
45 \\
34\end{array}$ & $\begin{array}{r}37 \\
16 \\
2 \\
20\end{array}$ & $\begin{array}{r}14 \\
19 \\
0 \\
21\end{array}$ & $\begin{array}{l}84 \\
53 \\
49 \\
77\end{array}$ \\
\hline
\end{tabular}

Injuries, like other non-inflammatory conditions, are rare in the first year of life. Burns and scalds occur almost entirely $(90 \%)$ in the age group $1-5$, while fractures occur chiefly $(76.3 \%)$ in the age groups 6-15. This is an expression of the different risks to which the school child and the pre-school child are exposed.

\section{Sex Incidence of Causes of Admission}

Tisdall et al. (1930) noted a general preponderance of males over females $(60 \%$ males) in most of the diseases they considered. In pyloric stenosis and tetany they found males in a much greater excess than this, and females exceeded males in pyelitis, primary peritonitis, endocarditis, chorea, typhoid, and pertussis. In considering the sex incidence of individual diseases, however, one must take account of the total preponderance of males over females at the ages concerned. The Registrar General's
Statistical Review for 1947 gives the sex ratio of males to females for children in England and Wales as follows: first year of life, 1.12; age group 1-5 years, 1.05; age group 6-10 years, 1.04; age group 11-15 years, 1-03. By applying these sex ratios to the age distribution of each disease an expected sex ratio for the disease can be obtained. This expected ratio is given in brackets for each disease represented by more than a hundred cases. The sex incidence of the chief diseases represented in this series is given in Table 5. This table confirms

TABLE 5

SeX Incidence of Diseases

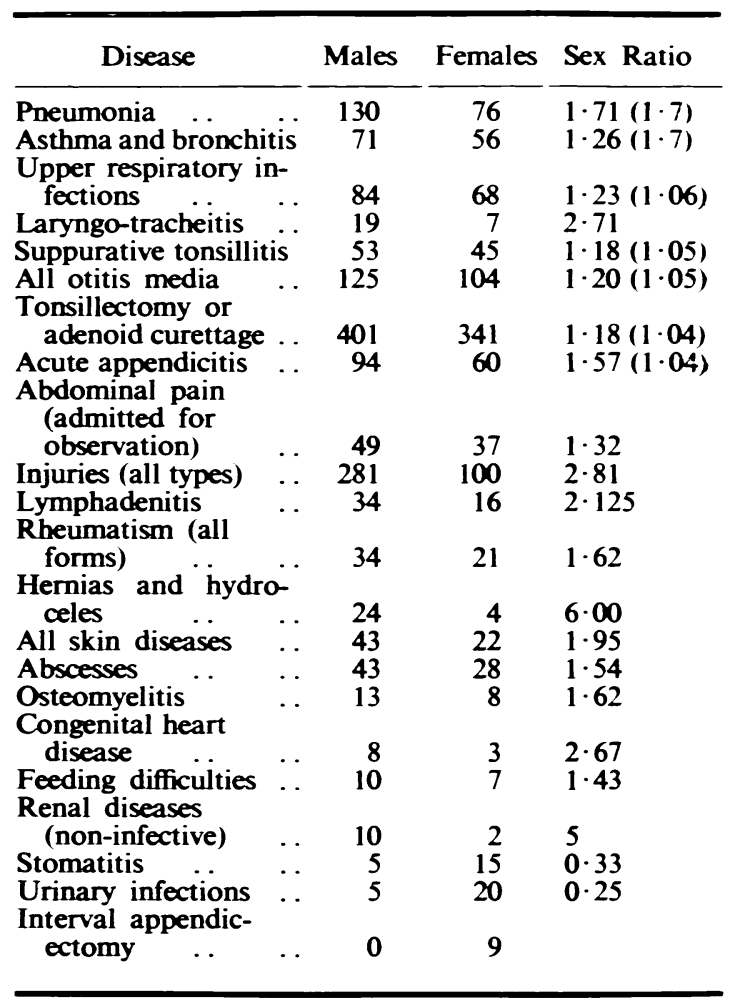

the general preponderance of males over females in most diseases as noted by Tisdall et al. (1930); the usual sex ratio appears to be about $1 \cdot 2$, not $1 \cdot 5$, as they found.

The diseases in which males are notably more preponderant are pneumonia, laryngo-tracheitis, acute appendicitis, lymphadenitis, rheumatism (all forms), hernias and hydroceles, skin diseases, abscesses, injuries, and some less common diseases. Females preponderated only in stomatitis and urinary infections. All the nine cases of interval appendicectomy were in females. 
Consideration of Some Less Common Diseases

Meningitis. There were 15 cases of meningitis in this series, of which two were tuberculous and five meningococcal. There were two pneumococcal cases, one being secondary to suppurative otitis media, and one secondary to a fractured base of the skull. There were two other suppurative cases from which no organisms were recovered, secondary to otitis media and pan-sinusitis respectively. From the remaining four cases Haemophilus influenzae (Pitman type B) was recovered; three of these occurred in the same month, and were apparently primary infections; the fourth a year later was secondary to acute mastoiditis. Three recovered; the fourth was moribund on admission.

Stomatitis. There were 20 cases of stomatitis, of which 14 were in the age group 1-5. In eight cases Vincent's organisms were found, in two cases staphylococci, in one case a streptococcus, and in one case a monilia.

Rheumatism (All Forms). Fifty-five cases under this heading were made up of 29 cases of acute and three of subacute rheumatism; ten acute cases with evidence of carditis, and five cases of chronic rheumatic endocarditis. There were eight admissions for chorea, in one of which there was a coincident rheumatic carditis.

Congenital Heart Disease. There were 11 cases under this heading, six cyanotic, three acyanotic, and two cases in which the cyanosis was doubtful.

Congenital Pyloric Stenosis. There were two cases of this condition, both females; the babies recovered after Ramstedt's operation.

Intussusception. There were seven cases of intussusception, five in the first year and two in the second year of life. All recovered after operation.

Volvulus. There was one case of this condition, in a boy of 14; the volvulus was secondary to tuberculous mesenteric adenitis.

Empyema. There were two cases of empyema, in a girl of 11 months and in a boy of 14 years.

Congenital Syphilis. There were two cases of this condition, born in different hospitals. In one case the mother had a negative Wassermann reaction before labour, but had failed to reveal that she was undergoing active anti-syphilitic therapy at the time.

Leukaemia. Only one case of this condition, lymphatic in type, was admitted during the period under review.

Tuberculosis. The 25 cases in which this condition was diagnosed consisted of five cases of primary, pulmonary tuberculosis, two cases of tuberculous meningitis, and one of miliary tuberculosis; four cases of cervical adenitis were regarded as tuberculous; two cases of tuberculosis of bone and one tuberculous ulcer of the arm. Three cases of tuberculous mesenteric adenitis were seen at operation. There were seven cases of lymphocytic pleural effusion.

Skin Diseases. There were 65 children with skin diseases. Nineteen of these had cellulitis, ten urticaria, seven infantile eczema, six impetigo, five erythema nodosum, four allergic purpura, and three erythema multiforme. There were two cases each of pustular rashes, scabies, angio-neurotic oedema and psoriasis, and one case each of seborrhoeic dermatitis, herpes simplex, and sunburn.

Osteomyelitis. There were 21 admissions due to this condition in the acute stage.

Laryngo-Tracheitis. Twenty-six children were admitted with stridor as the predominant symptom, of which ten were in the first year of life, and 13 in the age group 1-5 years. Two of these cases gave cause for grave anxiety, but both responded to inhalation of a penicillin spray in an oxygen tent.

Other Conditions. There was one case each of septicaemia, fibrocystic disease of the pancreas, cerebral abscess, cerebellar abscess, umbilical sepsis, regional ileitis, ulcerative colitis, neurofibromatosis, pseudohypertrophic muscular dystrophy, acute encephalitis, and a solitary cyst of the humerus with a pathological fracture.

Infections Fevers. There were 80 admissions under this heading, mostly admitted before diagnosis was possible. There were 22 cases of measles, 13 of whooping cough, 12 of non-specific infective enteritis, 11 of infective hepatitis, six of diphtheria, two each of typhoid fever, paratyphoid, chicken pox, Sonne dysentery, scarlet fever, anterior poliomyelitis, and one each of rubella, glandular fever, mumps, and $B$. Proteus diarrhoea.

Appendicectomy and Abdominal Pain. In 154 cases of appendicectomy the appendix was found to be acutely inflamed while in 31 cases the appendix was normal. In 24 of these latter there was a mesenteric adenitis, which in two cases appeared to be tuberculous. Meanwhile 86 children with abdominal pain were admitted for observation but discharged without operation.

Other Surgical Cases. Patients admitted with hernias and hydroceles numbered 28 . There were 19 orthopaedic cases, and 27 admitted for surgical conditions of the nose and ears. There were nine cases of interval appendicectomy, 17 other general surgical cases, and four dental cases.

\section{Fractures}

The patients with fractures who were admitted to hospital do not give a complete picture of their occurrence in children. Those treated as outpatients at the fracture clinic of the hospital have 
therefore been included, raising the total number to 288 . The age and sex distribution of the different sites of fracture are given in Table 6.

TABLE 6

Age (Years) and Sex Distribution of Fractures of LIMBS

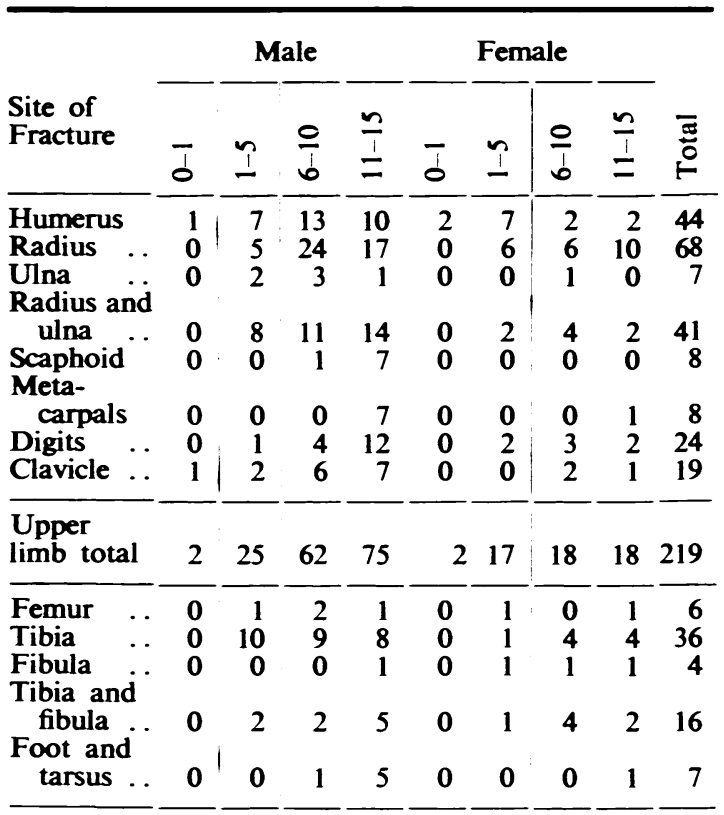

Lower

$\begin{array}{llllllllllll}\text { limb total } & 0 & 13 & 14 & 20 & 0 & 4 & 9 & 9 & 69\end{array}$

\begin{tabular}{lllllllllll}
\hline Total & $\ldots$ & 2 & 38 & 76 & 95 & 2 & 21 & 27 & 27 & 288
\end{tabular}

There were only four cases of fracture in the first year of life, three of the humerus and one of the clavicle. In the other age groups the incidence among females was fairly constant, whereas the incidence in males rose steeply with increasing age.

Fractures of the upper limb were three times as frequent as those of the lower limb. The most frequent bones affected were the radius and ulna (116 cases); next came the tibia and fibula (56 cases), then the humerus (44 cases), the hand and carpus (40 cases), the clavicle (19 cases), the foot and tarsus (seven cases), and the femur (six cases). Of the fractures of the humerus nearly half were supracondylar.

\section{Results}

In this series of 3,159 cases there were 46 deaths. In addition 169 children were transferred to other hospitals, 110 with infectious diseases, 45 for long term treatment, and 14 for special kinds of therapy. The causes of death by age groups are given in
Table 7 in order of frequency. Over half the deaths occurred in the first year of life, and half of these were due to pneumonia.

TABLE 7

Causes of Death

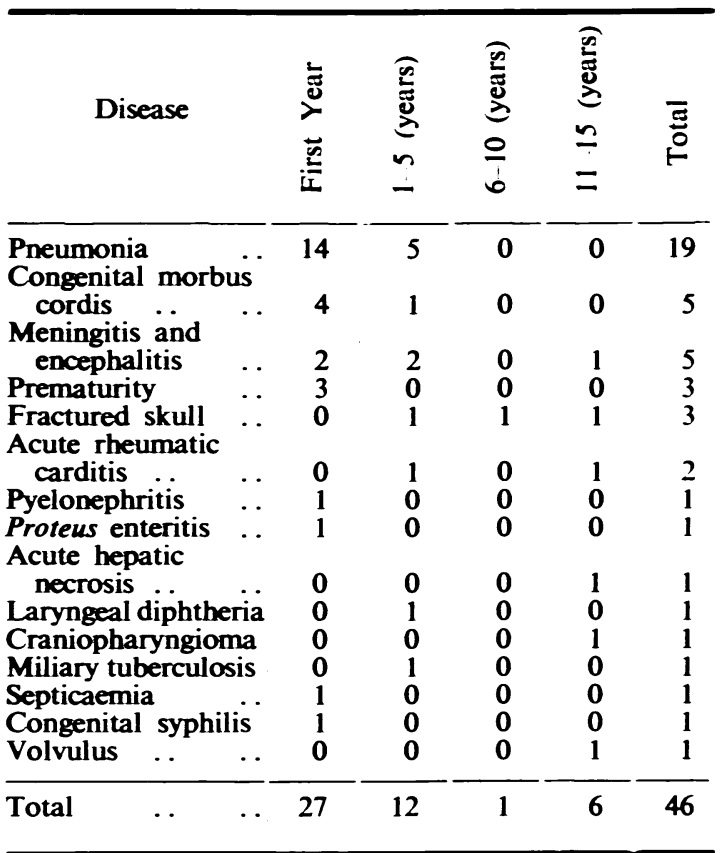

\section{Discussion}

When the word 'morbidity' is applied to adults it usually refers to the cause and duration of absence from work. However absence from school is not a reliable index. There can be no better criterion of morbidity in the school and pre-school child than admission to a general hospital, which admits both the more and the less severe ailments. It is claimed that this series gives a good overall picture of disease in childhood in east London.

It can be seen from this analysis that the causes of child morbidity can be divided into three groups according to their frequency. First the most common diseases of childhood, otitis media, respiratory infections, suppurative tonsillitis, injuries and acute appendicitis, which together account for 1,347 cases $(42 \cdot 8 \%)$. Secondly various groups of diseases represented in this series by from 10 to 80 cases each; these include abscesses (71 cases), skin diseases (65 cases), rheumatism (55 cases), cervical adenitis ( 50 cases), acute gastritis ( 29 cases), hernias and hydroceles (28 cases), urinary infections (25 cases), laryngo-tracheitis (26 cases), osteomyelitis (21 cases), and some dozen other conditions. This group amounts in all to 517 cases 
$(16.46 \%)$. The third group contains uncommon or rare diseases, either absent from this series, or represented by occasional cases only. These account for perhaps $4 \%$. The remaining $36 \%$ consist of short term admissions for circumcision, for tonsillectomy, for continuance of breast feeding, or for observation.

The preponderance of males over females is not unexpected. It is well known that male deaths are in excess of female deaths at all ages. While this preponderance is shown to some extent throughout, it is very much greater in several of the common diseases; the conditions in which females predominate are, on the other hand, of less frequent occurrence. Males predominate to a much greater extent in pneumonia than in bronchitis. The predominance of males in acute appendicitis is also noteworthy.

That males are more frequently injured than females is well known. It appears, however, from the analysis of the incidence of fractures (Table 6) that after the first year of life the female incidence is constant, while the male incidence rises steeply with age. Burns and scalds requiring admission occur almost exclusively between 1 and 5 years of age; of these two-thirds are in boys also. The rising incidence of fractures with age in boys can be seen to result chiefly from an increased frequency of fractures of the carpus, hand and foot in the higher age groups: these number in this series three in the age group 1-5, nine in the group 6-10, and 35 in the group 11-15; these fractures are much commoner in boys ( 38 cases) than in girls (nine cases). Fractures of the forearm show a less marked relationship to age, whereas fractures of the humerus, femur, and leg show a constant incidence after the first year of life. Most sites of fracture are two to three times as common in boys as in girls. However, there is a special liability of boys to fractures of the clavicle ( 16 boys to three girls), as well as of the carpus, hand, and foot ( 38 boys to nine girls).

\section{Summary}

Child morbidity has been studied by the analysis of the admissions of children to a general hospital over a period of two years.

The age incidence of the commoner diseases is described, and the age and sex incidence of fractures, burns, and other injuries are briefly mentioned, and the frequency of their occurrence approximately assessed.

I should like to thank Dr. F. A. Bryning, Medical Superintendent of Hackney Hospital, for permission to publish this paper, and Dr. P. B. Newcomb, senior physician to Hackney Hospital, for advice in its preparation.

\section{REFERENCES}

Baber, M. D. (1939). Archives of Disease in Childhood, $14,40$.

Collins, S. D. (1948). Publ. Hlth. Rep., Wash., 63, 637. Smellie, J. M. (1949). Proc. R. Soc. Med., 42, 636.

Tisdall, F. F., Brown, A.. and Kelly, A. D. (1930). Amer. J. Dis. Child., 39, 163. 